\title{
REPRODUCTIVE BIOLOGY OF THE MANTIS SHRIMP ERUGOSOUILLA MASSAVENSIS FROM PORT SAID, EGYPT.
}

\author{
Wafaa S. Sallam \\ Department of Marine Science. Faculty of Science, Suez Canal \\ Lniversity. Ismailia. Egypt. \\ Email address: 19..manallam ir ahorocum
}

Key words: reproduction. mantis shrinup. Erugosquilla. Egypt.

\section{ABSTRACT}

T The reyroductive biology of the mantis shrimp Erugosquilla masscrensis inhabiting the Mediterranean Sea at Port Said was studied and compared to prevjous studies. A single reproductive period was observed for females that lasted from February to August. This was followed by a well-derined resting phase from September 10 November. The ratio of males and females was nearly equivalent (0.95 female: 1 nale). Females outnumbered males in all months except during the reproductive season. Gonad indices as well as the number of females with developed cement glands were relatively. high during the spawning season. The body size at which $50 \%$ of females were sexualy mature was much smaller than that reported in a previous siudy (22.6 mm CL and $25.7 \mathrm{~mm} \mathrm{CL}$ respectively). Females responded to exiensive cxploitation by reaching maturity at a smaller size and by increasing fecundity. The mantis shrimp population in Port Said appears so far seriously heavily cxploited and needs urgent management regulations for the maintenance of that valuable tishery resource.

\section{INTRODLCTION}

Siudies on the reproductive biology of crustaccans provide essential information for understanding their reproductive pattern and strategies (Kawamurạ 'l al. 1997). They are panticularly important for species that have a fisher potential. Extensive studies have been carried out for a number of commercially economic species of slomatopods. The lapanese species (Jorosymilla oratoriu has heen extensively studied since it is considered as the mosi exploited 
stomatopod crustacean in the world (Hamano. etal. 1987; Ohtomi \& Shimiz1. 1991 : Torisawa et al. 1998). At the same time. considerable attention has been given to the mantis shrimp Squilla mantis due to its obvious abundance in the Mediterranean waters. The annual sexual cycle of this species has been investigated and analysed to a considerable extent (Do-Chi. 1975 : Giovanardi \& Manfrin. 1983) and subsequently related to fishery studies (Abello \& Sarda. 1989: Abello \& Martin, 1993).

The different aspects of reproductive biology are important factors in determining the reproductive potential of a species. and in understanding the interaction between its population and the environment. Erugosquilla massavensis (Kossmann, 1880) is a common stomatopod species in the Mediterranean Sea at Port Said. Sallam (2000) carried out a comprehensive study of its reproductive cycle and demonstrated that females of this species mature at much smaller size than those inhabiting the Suez Canal as a tesult of the high fishing mortality exerted on them. On the other hand. ElGanainy et al., (2004) studied the population dynamics of this species and concluded that its fishery is subjected to heavy exploitation. Therefore, the aim of this paper is to follow up the adaptability of this species stock and to elucidate certain aspects of its reproduction. including sex ratio. seasonality of reproduction and fecundity.

\section{MATERIALS AND METHODS}

Specimens of Erugosquilla massavensis were collected monthy from the Mediterranean coast at Port Said during the period from August 2002 to July 2003. All shrimps were first sexed then measurements of the total wet body weight (TW) and carapace length (CL) were taken for each specimen. Females were dissected and developmental stages of the ovaries were categorized into four arbitrary stages (immature-maturing- mature- ripe) according to Do chi (1975) and Sukumaran (1987). The cement glands of females which were reported to have a cyclic activity correlated to vitellogenesis (Deecaraman \& Subramoniam,1983) were examined and their stages of development were recorced. No females carrying egg masses were sampled during the present study. Fecundity was therefore estimated as the total number of ripe ova in the ovaries (i.e. in their last stage of maturity). A subsample of the ovary was taken. weighed and the number of ova was counted. The remaining ovary was subsequently weighed and the total number of ova calculated. 


\section{REPRODUCTIVE BIOLOGY OF THE MANTIS SHRIMP ERUGOSQUILLA MASSAVENSIS FROM PORT SAID \\ Gonad Index (GI) was calculated for each female as follow's:

$$
\mathrm{GI}=\frac{\text { Ovary wet weight }}{\text { Total wet body weight }} \times 100
$$

\section{RESULTS}

\section{Sex ratio:}

Figure 1 shows the monthly varjations in the sex ratio for Erugosquilla massavensis in Pon Said. Fenales outnumbered males in all months except November and during February-April. Of the whole catch (1997 specimens). 974 were females $(48.8 \%)$ and 1023 were males $(51.2 \%)$. Throughout the study, the total number of females was almost equivalent to the total number of males 10.95 female: 1 male). The ratio showed insignificant difference $\left(A^{2}=36.8\right.$. d.f. $=11 . P>0.05$ ).

\section{Size at first sexual maturity:}

The 974 female Erugosquilla massavensis examined, ranged in carapace length (CL) from 14.0 to $30.5 \mathrm{~mm}$ CL. Of these. $\$ 69$ females were in sexually mature stage. The relationship between carapace length $(\mathrm{CL})$ and the proportion of mature female $(P)$ by $m m$ CL classes was calculated by fitting a logistic function to the size specific maturity data for females (Fig.2) as follows:

$P=1 /(1+\exp [6.49-0.28 C L])\left(\mathrm{r}^{2}=0.75 . P<0.001\right)$

From this. the estimated size for $50 \%$ sexually mature females was $22.6 \mathrm{~mm} \mathrm{CL}$.

\section{Seasonality of spawning and cement glands development:}

The monthly variations in the percentage of sexually mature females (Fig. 3) shows a single reproductive period. lasting from February to August. $50 \%$ of females were mature during May August. This perind of reproductive activity was followed by a welldefined resting phase lasting from September to November. Development of cement glands also followed the same trend of gonadal maturation The annual changes in the percentage of female. with regard to the different maturation stages. (Fig. 4) demonstraicd that females with immarure. undeveloped ovaries (stage fl oecurred all the vear round and were most common between SeptemberJanuary. The beginning of the ovarian development (females in stage II) was observed to take place in December. The number of females increased regularly to reach their maximum in luly and then coclined to disappear completely during Octuber and November. Females in stage IIl were seen mainly from February to August. with a 
pronounced peak in June while females with ripe ovaries (stage IV) were only observed between April and June.

Gonad index:

The monthly changes in the mear gonad indices of females over the study period (Fig.5) were proved to be highly significant ( $F=$ 20.94. d.t. $=11 . P<0.001)$. A clear seasonal cycle was discernible for females. Gonad indices were relatively high during February August that coincides with the peak percentage of females in spawning condition (Fig. 2). The values declined in September and retained their low levels till January. The highest mean G.I. recorded was 3.9 in June and the lowest was 0.3 between November and January:

Fecundity:

Table 1 shows the relationship between carapace length. total weight, gonad weight and number of ripe ova for females. The total number of ripe ova ranged from 80372 in a female of $18.1 \mathrm{~mm} \mathrm{CL}$ with an ovary weight of $1.76 \mathrm{~g}$. to 217344 in a female of $29.7 \mathrm{~mm} \mathrm{CL}$ with an ovary weight of $5.67 \mathrm{~g}$. Fecundity showed an obvious increase with increasing carapace length. A tendency for the heavier females to become more fecund was also observed.

\section{DISCUSSION}

The sex ratio of E. massavensis in Port Said waters showed the presence of an excess of females for most of the year. Nevertheless. the ratio of females to males decreased during the spawning season (February - April) (Fig.1). Departure from a $1: 1$ ratio has been observed in gonodactylids and has been attributed to increased mortality in males that experience higher mortality due to the cost of searching for a new cavity every time they breed (Caldwell. 1986). Males outnumbered females during the breeding season, when females were brooding their eggs and remained in their burrows. This pattern agrees with those observed in other stomatopod species (Hamano \& Matsuura. 1987; Froglia \& Giannini, 1989; Dittel, 1991; Wortham-Neal, 2002) and with previous studies on E. massavensis of the Mediterranean (Sallam, 2000; El-Ganainy et al., 2004).

On the other hand, size at onset of females sexual maturity was observed to fall within the $15 \mathrm{~mm}$ CL size class ( $96 \mathrm{~mm} \mathrm{TL}$ ). The body size at which $50 \%$ of females were mature was estimated as $22.6 \mathrm{~mm}$ CL (125.1 mm TL) compared to $25.7 \mathrm{~mm}$ CL reported in a previous study (Sallam, 2000). It is therefore apparent that the 


\section{REPRODUCTIVE BIOLOGY OF THE MANTIS SHRIMP ERUGOSOLILLA MASSAVENSIS FROM PORT SAID}

intensive fishing of this shrimp in Port Said exerts a serious stress over females thus resulting in their earlier maturation. The continuous high fishing mortality of this species at this area has led females to select for sexual maturity at such smaller size to ensure the persistence of the stock. Early maturation as a result of overfishing could be considered an appropriate response to the factors that might limit reproductive success. Similar pattern has been reported for the Japanese mantis shrimp Oratosquilla oratoria in Tokyo Bay (Ohtomi and Shimizu. 1991).

Breeding of $E$ massarensis in Port Said is clearly seasonal. The pattern of gonad maturation, supported by variations in the gonad indices of females. displayed a clear existence, of an amnual reproductive cycle. The breeding season extended from FebruartAugust and was followed by a well-defined resting phase from September to November. Such seasonal pattern is in agreement with mosi previous studies on other stomatopod species (Hamano, et al.. 1987 : Torisawa el al., 1998). In the meantime. synchronous development and activity of the cement glands with gonadal maturation of females was observed. Similar synchrony has been recorded in other stomatopod species (Do-chi. 1975: Deecaraman. 1983: Caldwell. 1986: Wartham-Neal. 2002). Caldwell (1991) reported that activity of cement glands in stomatopod crustaceans correlated to gonad maturation may be considered as a secondary sexual character and that their packed white appearance when ful!! developed. clearly risible through the exoskeleton. provides a convenient means of determining when females are ready to spawn.

Estimates of fecundity for females $E$. massavensis in this study were observed to be higher than those reported in a previous study. (Sallam. 2000). It was also high if compared to estimates for other stomatopods (Giovanardi \& Piccinetti Manfrin. 1983; Hamano et al.. 1987). The high fecundity of large stomatopod species has been reported to suggest extraordinarily high juvenile mortality (Reaki. 1979). Sallam (2000) proposed that the higher fecundity of females $E$. massarensis might be an adaplive response to the intensive exploitation of this species in this area. The high fishing mortality in the Mediterranean could have resulted in females selecting for higher fecundity in order to ensure the continuity of their existence. Similar adaptive response has been reported in several commercially exploited fish populaimons (Garrod \& Horwood. 1984).

Despite the factors that could limit reproductive success. Fomales Enusosagialla massanensis in Pon Said area appeared a adapt 
eftectively to their surrounding environment and exhibited a fair ability in responding to exploitation. However. it is evident that the population of this species is heavily exploited and the regulation of its tisher: appears to be an immediate necessity.

\section{ACKNOWLEDG.MENT}

The author wishes to acknowledge Mr. Mohammad Yossri at the department of Science. Suez Canal University for his help in the statistical analysis.

\section{REFERENCES}

Abello. P. and Martin. P. (1993). Fishery of the mantis shrimp Squilla mantis (Crustacea: Stomatopoda) population off the Ebro delta (Northwestern Mediterranean). Fish. Res, 16:131-145.

Abello. P. and Sarda, F. (1989). Some observations on the biology and fishery of Squilla mantis L. in the Catalan area (NW Mediterranean Sea).In, E.A. Ferrero (ed.,). Biology of Stomatopods. Mucchi, Modena, pp.229 - 239.

Caldwell, R.L. (1991). Variation in reproductive behavoiur in stomatopod Crustacea. In. Crustacean sexual biology. R.T. Bauer and J. W. Martin (eds). Columbia University Press. New York. pages: $67-90$.

Deecaraman. M. and Subramoniam, T. (1983). Synchronous development of the ovary and the female accessory sex glands of a crustacean Squilla holoschista. Pro. of the Ind. Acad. of Sci. (Anim. Sci.) 92, (2): $179-184$.

Dittel, A.I. (1991). Distribution, abundance and sexual composition of Stomatopods in the Gulf of Nicoya, Costa Rica. J. of Crust. Biol., II (20): $269-276$.

preliminaires sur le cycle biologique benthique de Squilla mantis (Crustacea, Stomatopoda) dans le nord du Golfe du Lion.C. r. hebd. Seanc. Acad. Sci., Paris, 280:1729 - 1732

El-Ganainy,A.A., Sallam. W.S. and Yassin, M. (2004). Population dynamics of the mantis shrimp Erugosquilla massavensis 
(Crustacea: Stomatopoda) from the Eastem Mlediterrancian Sea. Egypt. The third International Conterence on Biological Science. Tanta lniversity (In Press).

Froglia. C. and Giannini. S. 11989). Field observations on dicl rhythms incatchability and feeding of Sauilla mamis (l..) Crustacea. Stomatopoda in the Adriatic Sea. In. E.A. Forroro (ed..). Biology of Stumatopods. Muccho. Modena. pp.221. 228.

Garrod. D. J. and Harwood. J. W. (1984). Reproductive strategies and the response to exploitation. In. Fish reproduction strategics and tactics. Potts. E. W. and Wotton. R. J. (eds). Academic Press INC. London. PP. $367-384$.

Giovanardi. O. and Piccinetti Manfrin. G. (1983). Summary of biological paraneters of Squilla mantis $\mathrm{L}$. in the Adriatic Sea. Fish. Res. (2) $131-\{34$.

Hamano. T. ; Morriss: M.M., and Matsuura. S. (1987). Ecological information on Orarosquilla oraroria (Stomatopoda. Crustacea) with an attempt to estimate an annual settlement date from growth parameters. Journal of Shim. Uni. of fish. 36 : $9-27$.

Kawamura. Y. ; Hamano, T. and Kagawa. T. (1997). Distribution of larvae and juveniles of the Japanese mantis shrimp Oratosquilla orctoria (De Haan, 1844) (Stomatopoda) in the Sea of Hiuchi-Nada, Japan. Crust. Res., 26:75-82.

Ohtomi, J. and Shimizu. K. (1991). The spawning ground of the Japanese mantis shrimp Oralosquilla oratoria in Tokyo Bay. Nipp.Sui. Gakk., 57(3):447-451.

Reaka, M.L. (1979). The evolutionary ecology of life history patterns in stomatopod Crustacea. In. S.Stancyk (ed.,) Reproductive ecology of marine invertebrates, pp.235 - 260. Columbia. South Carolina: Belle W. Baruch Library in Marine Sciences. University of South Carolina Press. 
Sallam. W.S. (2000). Studies on the biology of mantis shrimps in the Suez Canal. Ph.D. thesis. Suez Canal University. Egypt. $121 \mathrm{pp}$.

Sukumaran. K.K. (1987). Study on the fishery and biology of the mantis shrimp Oratosquilla nepa (Latereille) of South Kanara coast during 1979-83. Fish. Biol.. 2:292-305.

Torisawa. M. : Mitsuhashi. M. and Nagai. Y. (1998). Spawning season of the Japanese mantis shrimp Oralosquilla oraroria (De Haan) in Ishikari Bay. Hokkaido, Japan. Nipp. Sui. Gakk. $66(3): 453-461$.

Mortham-Neal. 3.L. (2002). Reproductive morphology of male and fenale mantis shrimp (Stomatopoda: Squillidae). J. Crust. Biol. $\therefore 2(4): 728-741$. 


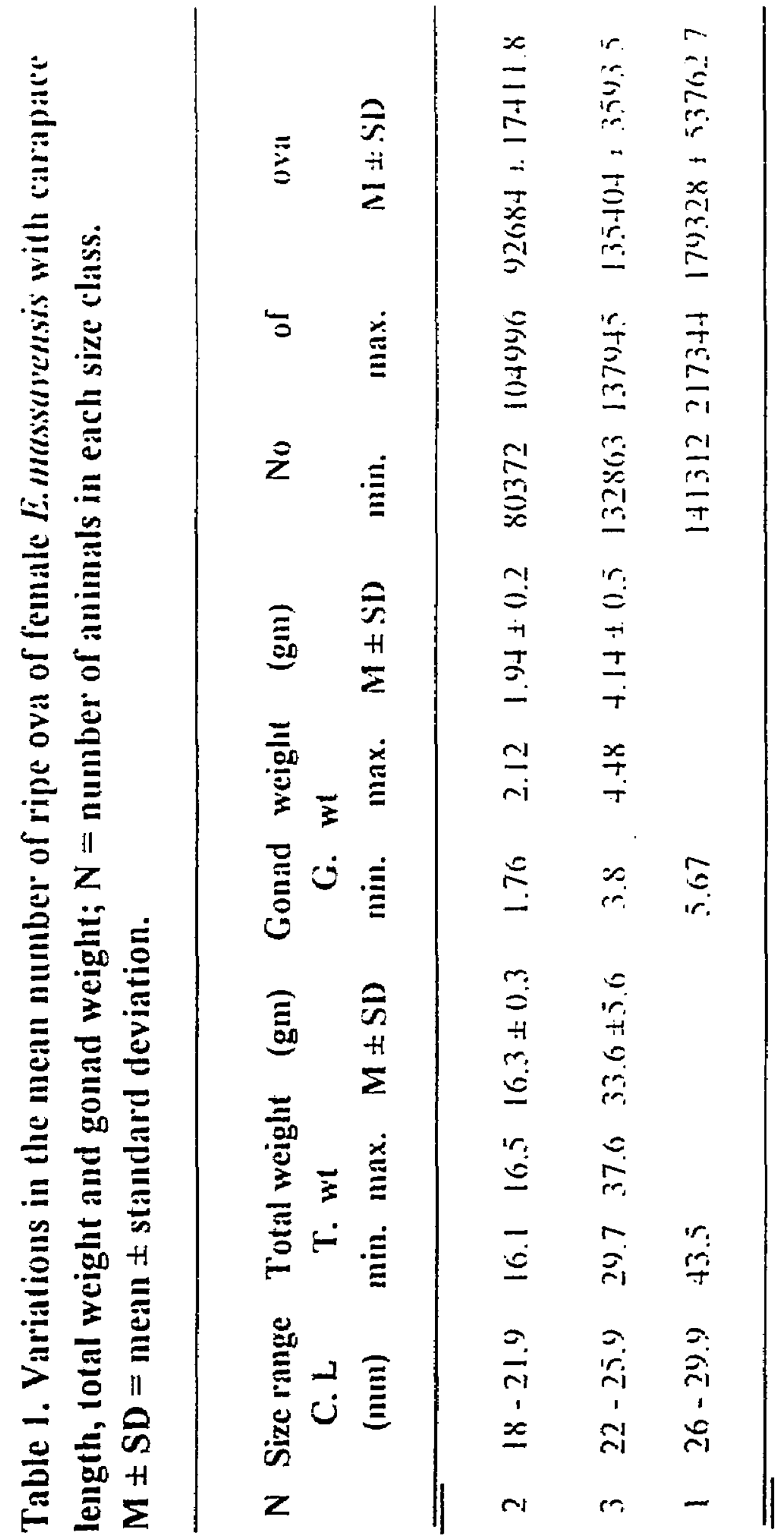




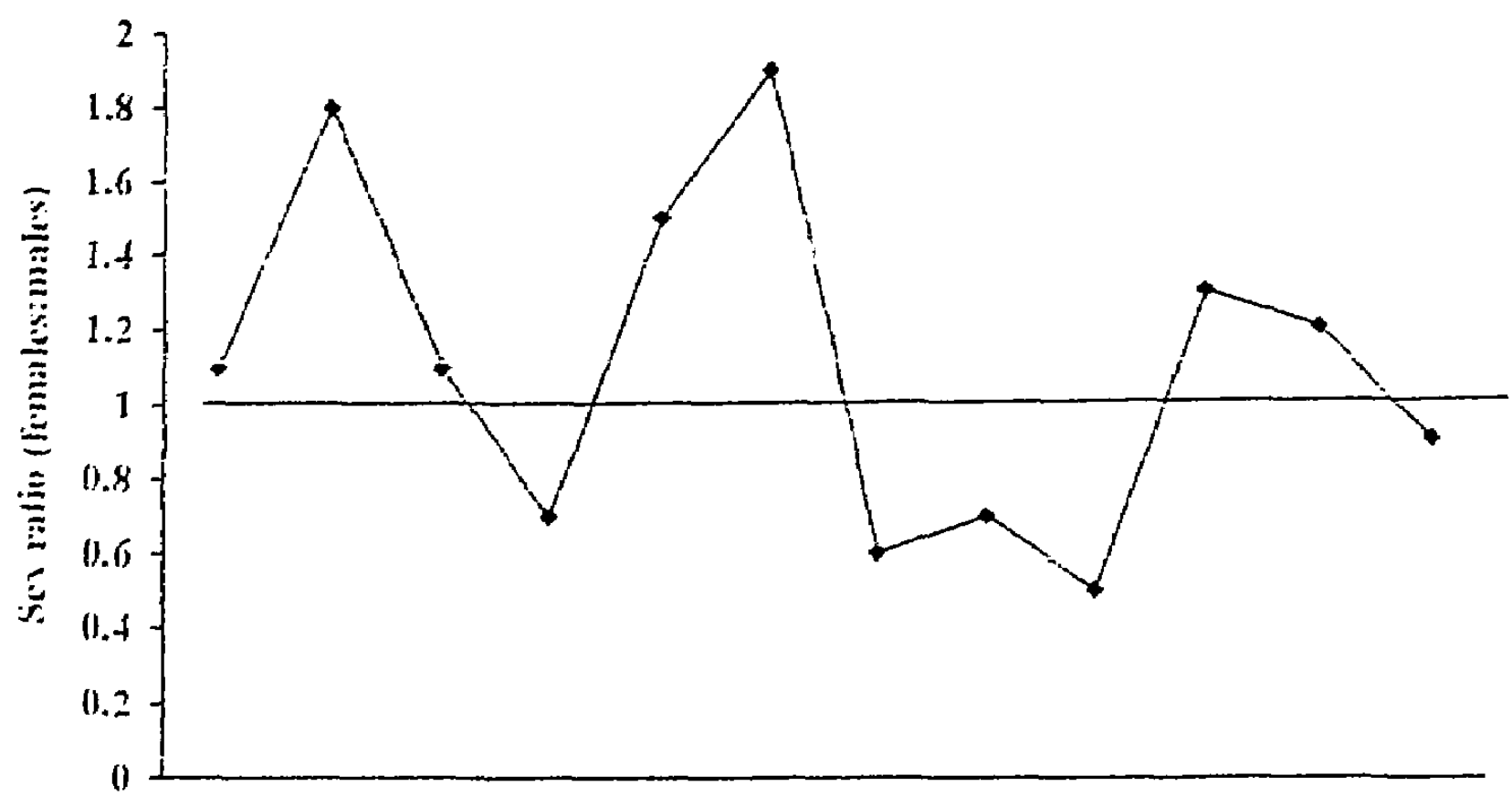

Aug. Scp. Oet. Non, Dec Jan. Feb. Mat: Aps. May Jun. Jul. Months

Fig. 1. Morthly variations in the sex ratio of $E$. massavensis. The line indicates a ratio of $1: 1$ (females:males)

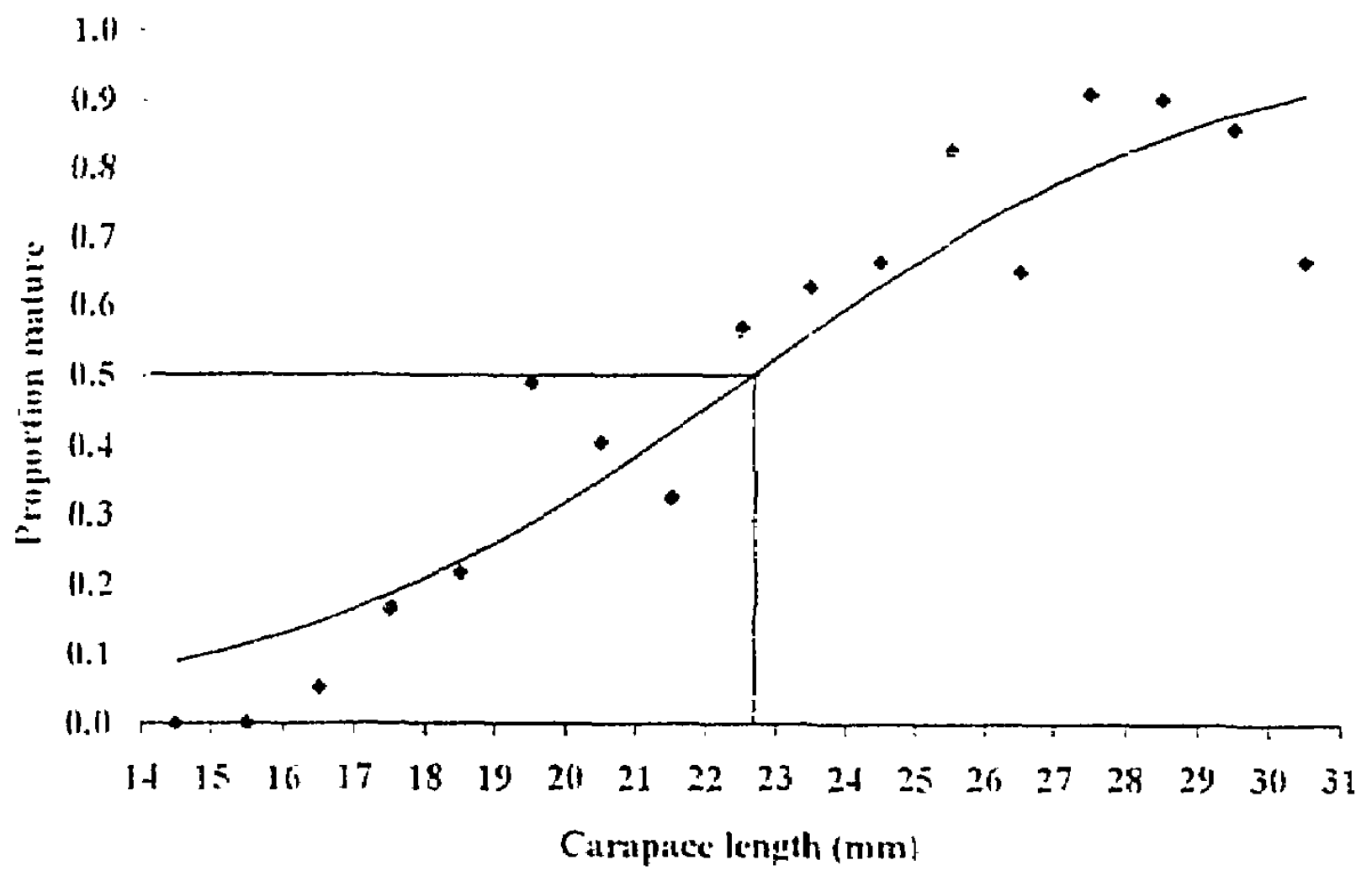

Fign 2. Logictic function fitting proportion of mature female to carapiace length. The value of $C L_{311}$ which correepend to a proportion of 0.5 is indicated. 


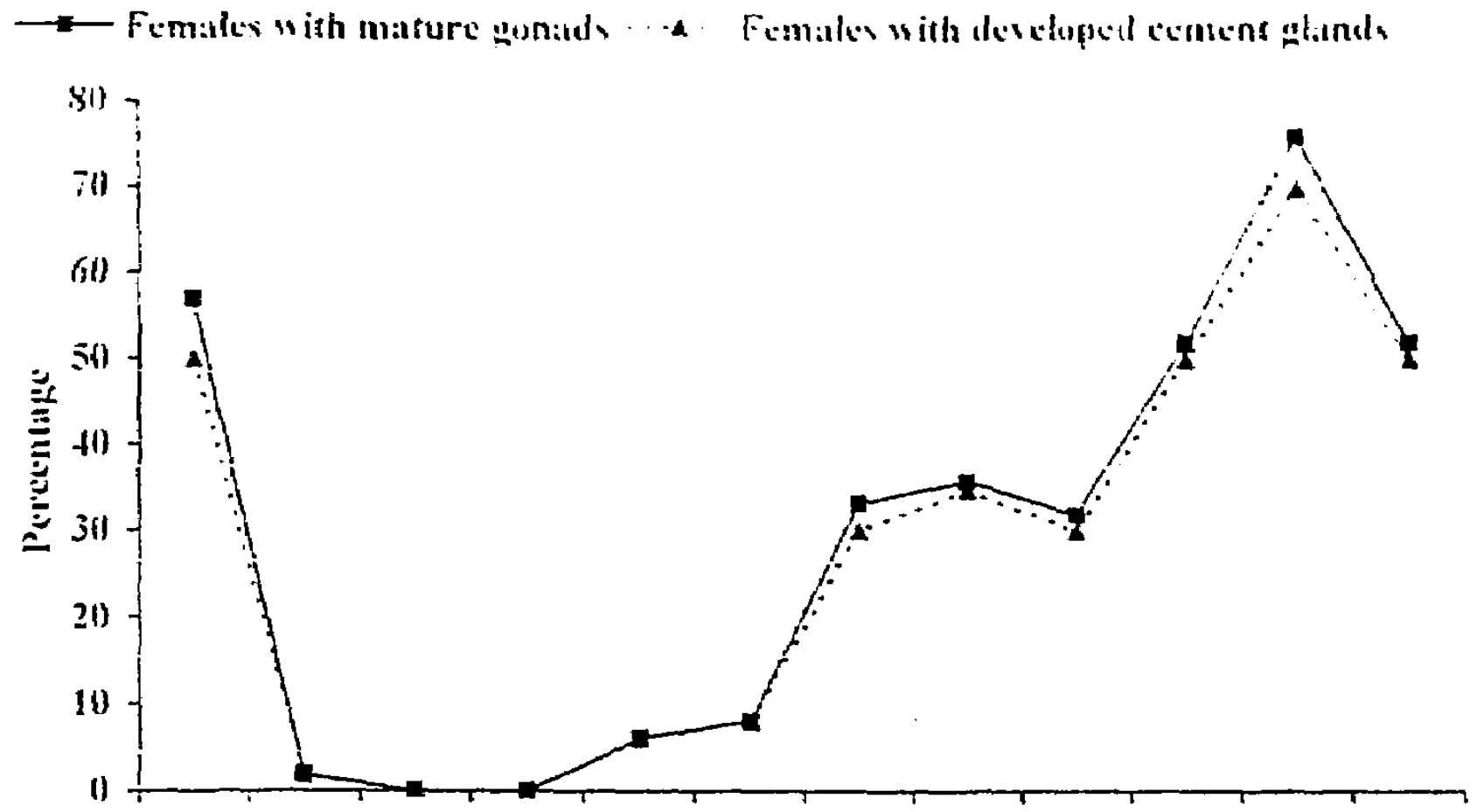

Aüg. Sep. Oet. Nov. Dec. Jañ. Fub. Mar. Apr. May Jun. Jul. Months

Fig.3. Wonthly changes in the pereentages of females with marure gonads and with developed cement glands.

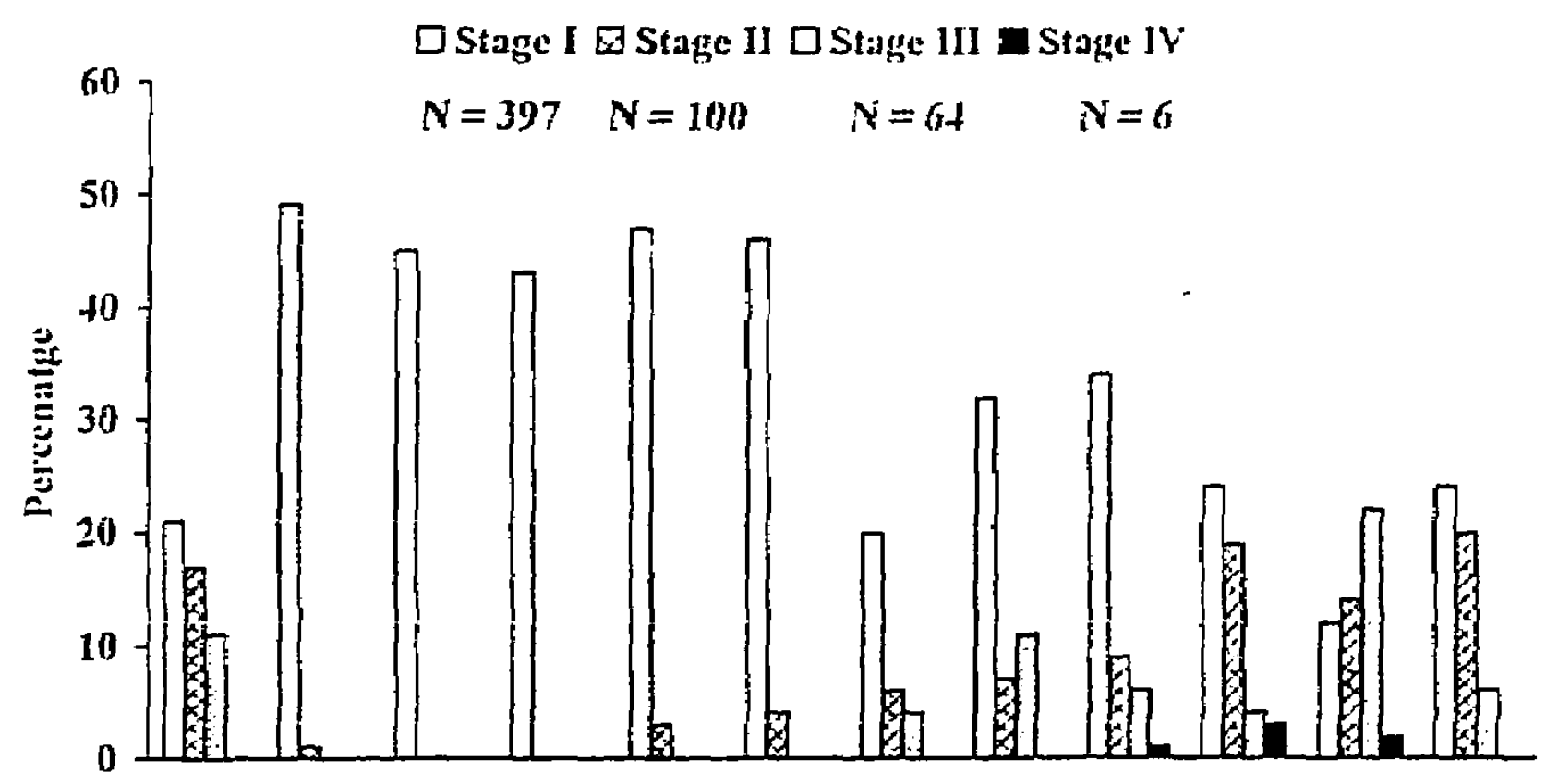

Aug. Sep. Oct. Nov. Dec. Jan. Feb. Mar. Apr. May Jun. Jul. 2002 Months 2003

Fig. 4. Monthly variations in the percentages of females in each stage of gonad maturation. $N$, number of females cxamined in each stage. 
6

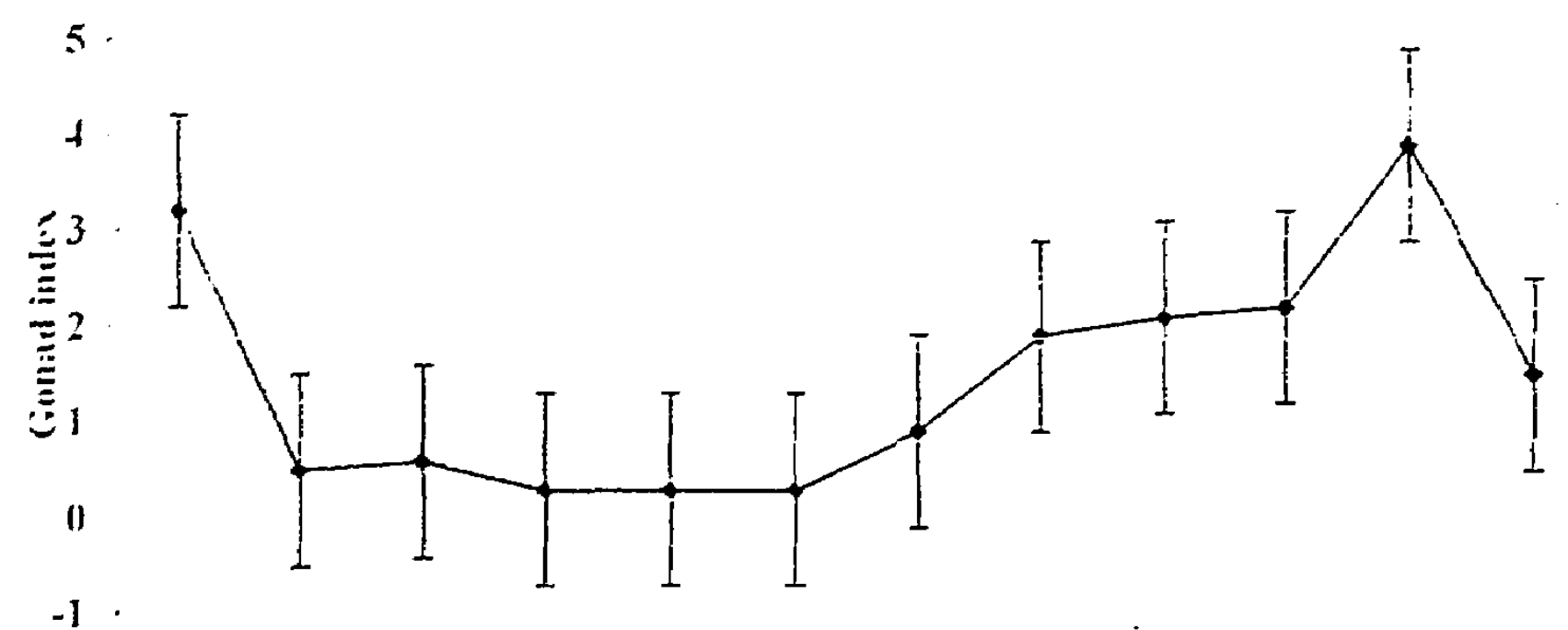

$-2$

Aung. Seq. Oct. Nox. Dec. Jan. Feh. Mar. Apr. May Jun. Jul. 2002 Months 2003

Fig. 5 Monthly changes in the gonad indices of females. Vertical lines indicate standard deviations. 